\section{Oral health of female prisoners in HMP Holloway: implications for oral health promotion in UK prisons}

\author{
P. Rouxel, ${ }^{* 1}$ D. Duijster, ${ }^{1,2}$ G. Tsakos ${ }^{1}$ and R. G. Watt ${ }^{1}$ \\ VERIFIABLE CPD PAPER
}

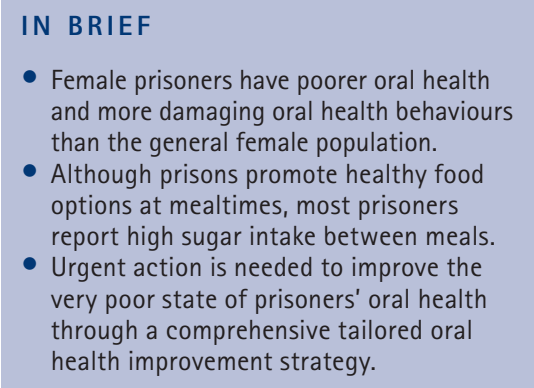

Objectives This study describes the oral health status and associated risk factors in a sample of female prisoners and compares their oral health to that of the female population from the 2009 Adult Dental Health Survey. Method A random sample of prisoners was selected from HMP Holloway, London. Structured interviews were carried out to collect information on oral health behaviours and oral health related quality of life. Clinical examinations using the Adult Dental Health Survey criteria assessed the oral health needs of prisoners. Results The mean age of female prisoners $(n=103)$ was $30.9 \pm 9.6$ years. The prevalence of oral diseases was high. Seventy-five percent had decayed or unsound teeth. The mean DMFT was $12.3 \pm 7.5$. Compared to the general female population, prisoners had more decayed and fewer filled teeth. Sixty-six percent had periodontal pockets of $4 \mathrm{~mm}$ or more. A large proportion (73\%) reported at least one oral impact on daily performances. Prisoners were more likely than the general female population to engage in oral health damaging behaviours such as high sugar intake and smoking. Conclusion This survey has demonstrated the poor state of oral health and identified considerable levels of unmet dental treatment needs in HMP Holloway. Urgent action is required to address this major public health problem.

\section{INTRODUCTION}

Oral health in the UK has been steadily improving over the last 30 years. However, during this period oral health inequalities have become a major public health concern. ${ }^{1}$ Oral diseases disproportionally affect socially disadvantaged groups in society and have a significant impact on quality of life and may affect individuals' eating and speech, self-confidence and social integration.

Available data suggest that the oral health of prisoners is generally poor and considerably worse than that of the general population. ${ }^{2-4}$ Detailed information on the oral health status of the UK prison population is, however, sparse. A systematic review has highlighted the general

'Department of Epidemiology and Public Health, University College London, Gower Street Campus, 1-19 Torrington Place, London, WC1E 6BT; ${ }^{2}$ Department of Preventive Dentistry, Academic Centre for Dentistry Amsterdam, University of Amsterdam and VU University, Gustav Mahlerlaan 3004, 1081 LA Amsterdam, The Netherlands

${ }^{*}$ Correspondence to: Patrick Rouxel

Email: patrick.rouxel.09@ucl.ac.uk

\section{Refereed Paper}

Accepted 8 May 2013

DOI: 10.1038/sj.bdj.2013.581

${ }^{\circ}$ British Dental Journal 2013; 214: 627-632 poor quality of oral health surveys in UK prisons and therefore the difficulty in comparing and drawing firm conclusions on the oral health of this population group. ${ }^{2}$ A random sample of prisoners from the North West of England ${ }^{3}$ showed that prisoners had twice as many decayed teeth (mean 4.2) than the general population (mean 1.9) based on data from the 1998 Adult Dental Health Survey (ADHS). Findings from the Scottish Prison's Oral Health Survey showed that prisoners had poorer oral health than the general population particularly in terms of untreated dental caries. ${ }^{4}$ Surveys have shown that prisoners are more likely to practise a range of health damaging behaviours such as smoking, poor oral hygiene and use of recreational drugs, all of which may contribute to poorer oral health. ${ }^{2,3}$ Before imprisonment, prisoners are more likely to be heavy drinkers and infrequent dental attenders.

The poor oral health condition of the UK prison population has led to the recognition that there is an urgent need to improve the quality of dental care in prisons and to develop effective oral health promotion policies. ${ }^{5,6}$ Therefore, this study aimed to conduct a comprehensive oral health needs assessment in HMP Holloway, as it is the largest women's prison in the UK. It acts as a closed local prison holding adult women and female young offenders on remand or sentenced by the inner London courts, and also operates as a first stage lifer centre. ${ }^{7}$

The objective of this study was to describe the oral health status, oral health behaviours and oral health-related quality of life of the prison population in HMP Holloway. For general discussion the findings were shown alongside to those from a representative sample of the female adult population from the 2009 ADHS. The 2009 ADHS is a representative sample of adults living in England, Wales and Northern Ireland. A subset of the ADHS female population with the same age range as the sample of prisoners was selected for comparison purposes. A further objective was to make detailed recommendations for the development of oral health promotion policies in UK prisons.

\section{METHODOLOGY}

This is a cross-sectional study. The fieldwork was conducted between July and August 2010 and coordinated by the UCL 
Department of Epidemiology and Public health and NHS Islington who currently provides dental care to HMP Holloway. Ethical approval was obtained from the UCL Ethics Committee and the National Offender Management Service (NOMS).

The survey sample size was calculated to enable to report reliable prevalence estimates of a range of oral health conditions. As the prevalence of caries in the Islington prison was unknown, data from a published UK study ${ }^{3}$ were used to determine the sample size. Jones et al. $^{3}$ found that $92 \%$ of the female prisoners had decayed or unsound teeth. Based on this prevalence, the calculated sample size for this study was 118 individuals with an estimate precision of $2.5 \%$. To compensate for recruitment problems we over-sampled by 30\% giving a target sample of 153 prisoners. In addition, the prison population involved two strata of prisoners: those on remand and those sentenced. Each stratum was allocated a sample size in proportion to its contribution to the total on remand or sentenced prison population.

Before the survey, the list of all female prisoners in HMP Holloway was provided from the prison (p-Nomis) database. There was a total of 416 prisoners from which the sample of 153 female prisoners aged 18 years and over was randomly selected. In addition, a second (back-up) list of randomly sampled and ordered prisoners was drawn up in the event that a sampled prisoner would have been released by the time of data collection and therefore be ineligible for participation. At the time of the survey the monthly turnover was about $30 \%$. Prisoners in the mother and baby unit were excluded for ethical reasons.

An information sheet giving an outline of the nature and purpose of the survey was given to all sampled individuals in advance of the survey. Prisoners were called up to the survey area and given a verbal explanation of the project by a member of the survey team. Two custodial officers were involved to facilitate the survey process. One officer brought in the selected prisoners while the other officer remained present in the waiting room, although not in immediate proximity or hearing range of the interview or examination. Participants signed a form giving their written consent before the interview and clinical examination were undertaken.

Table 1 Characteristics of the study population $(n=103)$

\begin{tabular}{|c|c|c|c|}
\hline & No & Percentage & Mean \pm SD \\
\hline Age group: years & & & $30.88 \pm 9.60$ \\
\hline $18-29$ & 52 & 50.49 & \\
\hline $30-39$ & 31 & 30.10 & \\
\hline $40-59$ & 20 & 19.42 & \\
\hline \multicolumn{4}{|l|}{ Ethnicity } \\
\hline White & 58 & 56.31 & \\
\hline Black & 29 & 28.16 & \\
\hline Others (mixed/Asian/Chinese) & 16 & 15.53 & \\
\hline \multicolumn{4}{|l|}{ Marital-status } \\
\hline Single & 65 & 63.11 & \\
\hline Married/civil partner & 22 & 21.36 & \\
\hline Separated/divorced/widowed & 16 & 15.53 & \\
\hline \multicolumn{4}{|l|}{ Educational level } \\
\hline None & 12 & 11.65 & \\
\hline Primary & 15 & 14.56 & \\
\hline Secondary & 25 & 24.27 & \\
\hline College/university & 51 & 49.51 & \\
\hline Age left full time education & & & $16.80 \pm 4.90$ \\
\hline Detention characteristics & & & $11.10 \pm 22.95$ \\
\hline Remand & 45 & 43.69 & \\
\hline Sentenced & 58 & 56.31 & \\
\hline \multicolumn{4}{|c|}{ Time spent in custody at time of interview } \\
\hline Less than 6 months & 47 & 46.08 & \\
\hline 6 months to 12 months & 10 & 9.80 & \\
\hline More than 12 months & 45 & 44.11 & \\
\hline
\end{tabular}

As Holloway is a working prison, a $£ 2.50$ incentive was paid to participants to cover potential loss of income.

A structured face-to-face interview, using a questionnaire, was conducted by a trained interviewer (DD). Information was collected on the prisoner's socio-demographic characteristics; oral health behaviours such as oral hygiene, diet, smoking and drug misuse; and oral health-related quality of life through the use of the oral impacts on daily performances scale (OIDP). ${ }^{8}$ The OIDP measures oral impacts on eating, speaking, cleaning teeth or dentures, relaxing, smiling, carrying out daily activities, going out, emotional stability and enjoying social contacts. The version used in this study was adapted for the specific group, by removing the performance 'going out'. Prisoners were asked if they had had any difficulties in any performance in the past six months due to problems with their teeth, mouth or denture.
Participants with an impact were also asked what had caused their difficulty. The questionnaire was piloted prior to the main interview with a small sample of prisoners who attended the prison dental service. Following the interview, the non-invasive clinical examination was carried out using the criteria developed for the 2009 ADHS. ${ }^{9}$ Collected clinical data included the number of natural teeth, condition of the crowns and roots, periodontal condition and presence of severely decayed teeth with visible pulpal involvement $(\mathrm{P})$, ulceration caused by dislocated tooth fragments (U), fistula (F) and abscess (A) - PUFA index..$^{10}$ One dentist (PR), previously trained by and calibrated with an ADHS survey trainer, carried out all examinations. The calibration was made in the same conditions of the survey within ten participants. The level of agreement was 93\% (Kappa score 0.83). Clinical data were recorded by a dental nurse. Data analysis 


\begin{tabular}{l} 
Table 2 Clinical oral health status of study sample and comparison with ADHS 2009 \\
\begin{tabular}{|l|l|l|l|l|l|}
\hline \\
Sound teeth
\end{tabular} \\
\hline
\end{tabular}

was performed using the statistical software Stata/SE 12.1, StataCorp. Descriptive statistics were used to describe the characteristics of the study sample.

\section{RESULTS}

Of the 153 prisoners selected to participate in the survey, 22 were already released at the time of the survey, 28 refused to participate, two were transferred to other settings, one was excluded as she did not speak English, one was too sick to attend and ten did not attend for other reasons. Therefore, from the 89 remaining participants, two were excluded from the analysis for not having completed the dental examination. Sixteen subjects on the backup list replaced some of those who were released. Thus, a total of 103 prisoners were interviewed and examined. This represented a $71.5 \%$ response rate and an estimated $25 \%$ of the total HMP Holloway prison population.

The mean age of women was 30.9 ( \pm 9.6). The ethnic breakdown revealed that the majority of those surveyed were white (56\%). Just over 10\% of women had never attended school or had only completed primary school education, and nearly half (49\%) had attained a university or college degree. The mean age that the respondents left full-time education was 16.8 years (range $0-28$ years). The average length of time served in prison at the time of the survey was 11.1 months (range 2 days-12 years 9 months) (Table 1 ).

\begin{tabular}{|c|c|c|c|c|}
\hline & \multicolumn{4}{|c|}{ Frequency of tooth cleaning } \\
\hline & Twice a day or more & Once a day & Less than once a day & Never \\
\hline HMP Holloway & $82 \%$ & $16 \%$ & $3 \%$ & $0 \%$ \\
\hline \multirow[t]{3}{*}{ ADHS 2009} & $77 \%$ & $21 \%$ & $2 \%$ & $0 \%$ \\
\hline & \multicolumn{4}{|c|}{ Usual reason for dental attendance } \\
\hline & Regularly & Occasionally & Only with trouble & Never been to dentist \\
\hline HMP Holloway & $33 \%$ & $23 \%$ & $41 \%$ & $3 \%$ \\
\hline \multirow[t]{3}{*}{ ADHS 2009} & $67 \%$ & $9 \%$ & $22 \%$ & $1 \%$ \\
\hline & \multicolumn{4}{|l|}{ Diet } \\
\hline & \multicolumn{2}{|l|}{ Low sugar intake } & \multicolumn{2}{|l|}{ High sugar intake } \\
\hline HMP Holloway & \multicolumn{2}{|l|}{$34 \%$} & \multicolumn{2}{|l|}{$66 \%$} \\
\hline \multirow[t]{3}{*}{ ADHS 2009} & \multicolumn{2}{|l|}{$54 \%$} & \multicolumn{2}{|l|}{$46 \%$} \\
\hline & \multicolumn{4}{|l|}{ Smoking status } \\
\hline & \multicolumn{2}{|l|}{ Current smoker } & Past smoker & Never smoked \\
\hline HMP Holloway & \multicolumn{2}{|l|}{$66 \%$} & $11 \%$ & $23 \%$ \\
\hline \multirow{2}{*}{ ADHS 2009} & \multicolumn{2}{|l|}{$26 \%$} & $26 \%$ & $48 \%$ \\
\hline & \multicolumn{4}{|l|}{ Drug use } \\
\hline HMP Holloway & \multicolumn{4}{|l|}{$50 \%$} \\
\hline ADHS 2009 & \multicolumn{4}{|l|}{$\mathrm{N} / \mathrm{A}$} \\
\hline
\end{tabular}

Table 2 summarises the descriptive clinical dental data. These findings were compared to those of the female sample from the 2009 ADHS using population weights. ${ }^{11}$ Overall the mean DMFT-score of the female prison population was 12.3 $( \pm 7.5)$ compared to $11.4( \pm 7.0)$ of the
ADHS. None of the selected subjects were edentate. On average the sample had 19.8 $( \pm 7.5)$ sound teeth. Forty-five percent of the participants had less than 20 sound teeth and only $16 \%$ had 28 or more sound teeth. An average of $2.5( \pm 2.5)$ teeth were decayed, twice the level found in the ADHS 
Table 4 Impact of oral health on daily performance in study sample and comparison with ADHS 2009

\begin{tabular}{|l|l|l|l|l|l|l|l|l|l|l|} 
& \multicolumn{2}{l|}{$\begin{array}{l}\text { At least one } \\
\text { oral impact }\end{array}$} \\
& eating & speaking & cleaning teeth & $\begin{array}{l}\text { carrying out } \\
\text { daily activity }\end{array}$ & relaxing & smiling & $\begin{array}{l}\text { emotional } \\
\text { stability }\end{array}$ & $\begin{array}{l}\text { enjoying } \\
\text { contact }\end{array}$ \\
\hline HMP Holloway & $55 \%$ & $11 \%$ & $18 \%$ & $5 \%$ & $30 \%$ & $37 \%$ & $32 \%$ & $20 \%$ & $73 \%$ \\
\hline ADHS 2009 & $21 \%$ & $6 \%$ & $16 \%$ & $5 \%$ & $12 \%$ & $16 \%$ & $6 \%$ & $6 \%$ & $33 \%$ \\
\hline
\end{tabular}

$(1.0 \pm 2.0), 5.0 \pm 4.9$ were missing, and $4.9( \pm 4.7)$ were filled. In terms of current disease prevalence, $75 \%$ of the female prisoners had decayed teeth compared to only $39 \%$ in the ADHS.

In addition to the DMFT, the PUFA-index was used to measure the prevalence and severity of oral conditions resulting from untreated dental caries. The prevalence of PUFA (percentage of the population with a PUFA score of one or more) in the sample was $40 \%$, more than five times higher than in the ADHS (7\%). More than 20\% of prisoners had a PUFA score of two or more. The mean PUFA-index in the sample was $0.8 \pm 1.4$. The main component of PUFA was pulpal involvement.

Over $60 \%$ of participants had some periodontal pocketing of $4 \mathrm{~mm}$ or more compared to $41 \%$ in the ADHS. Deep pockets (pocket depths of $6 \mathrm{~mm}$ or more) affected 15\% of prisoners, which was nearly three times higher than in the ADHS (6\%). Overall, $82 \%$ of prisoners had some calculus deposits compared to 69\% in the ADHS. Almost all prisoners (96\%) had gingival bleeding on probing while only 55\% of the ADHS female population had gingival bleeding.

Table 3 summarises the oral health and general health behaviours of the participants. When compared to the results of the ADHS, major differences were found in terms of patterns of health behaviours. Over 80\% reported brushing their teeth twice daily and only 3\% reported brushing less than once a day. The majority of the prisoners (97\%) reported they had attended a dentist. The main reason for visiting the dentist was when they experienced trouble (41\%). A third reported visiting the dentist for a regular check-up compared to 55\% in the ADHS. Overall, two-thirds of the prisoners (66\%) were current tobacco smokers, which is about three times higher than in the ADHS (26\%). Prisoners were asked whether they had ever used illegal drugs in the last six months before entering prison.

\begin{tabular}{|c|c|c|c|c|c|c|c|}
\hline \multirow[b]{2}{*}{$\begin{array}{l}\text { Daily } \\
\text { performances }\end{array}$} & \multicolumn{7}{|c|}{ Main oral impairments causing oral impacts } \\
\hline & & No & Percentage & $\begin{array}{l}\text { Daily } \\
\text { performances }\end{array}$ & & No & Percentage \\
\hline $\begin{array}{l}\text { Eating } \\
(n=57)\end{array}$ & $\begin{array}{l}\text { Toothache/ } \\
\text { sensitive tooth } \\
\text { Broken tooth } \\
\text { Missing tooth } \\
\text { Other }\end{array}$ & $\begin{array}{l}33 \\
9 \\
6 \\
9\end{array}$ & $\begin{array}{l}58 \% \\
16 \% \\
11 \% \\
16 \%\end{array}$ & $\begin{array}{l}\text { Smiling } \\
(n=38)\end{array}$ & $\begin{array}{l}\text { Missing tooth } \\
\text { Colour } \\
\text { Bad position } \\
\text { Broken } \\
\text { Other }\end{array}$ & $\begin{array}{l}14 \\
12 \\
5 \\
4 \\
3 \\
\end{array}$ & $\begin{array}{l}37 \% \\
32 \% \\
13 \% \\
11 \% \\
8 \% \\
\end{array}$ \\
\hline $\begin{array}{l}\text { Speaking } \\
(n=11)\end{array}$ & $\begin{array}{l}\text { Missing tooth } \\
\text { Toothache } \\
\text { Other }\end{array}$ & $\begin{array}{l}4 \\
3 \\
4\end{array}$ & $\begin{array}{l}36 \% \\
27 \% \\
36 \%\end{array}$ & $\begin{array}{l}\text { Carry out } \\
\text { daily activity } \\
(n=5)\end{array}$ & $\begin{array}{l}\text { Toothache/ } \\
\text { sensitive tooth } \\
\text { Other }\end{array}$ & $\begin{array}{l}2 \\
3\end{array}$ & $\begin{array}{l}40 \% \\
60 \%\end{array}$ \\
\hline $\begin{array}{l}\text { Cleaning } \\
(n=19)\end{array}$ & $\begin{array}{l}\text { Loose tooth/ } \\
\text { bleeding gums } \\
\text { Toothache/ } \\
\text { sensitive tooth } \\
\text { Other }\end{array}$ & $\begin{array}{l}6 \\
5\end{array}$ & $\begin{array}{l}42 \% \\
32 \% \\
26 \%\end{array}$ & $\begin{array}{l}\text { Emotional } \\
\text { stability } \\
(n=33)\end{array}$ & $\begin{array}{l}\text { Toothache/ } \\
\text { sensitive tooth } \\
\text { Missing tooth } \\
\text { Loose tooth/ } \\
\text { bleeding gums } \\
\text { Bad position } \\
\text { Other }\end{array}$ & $\begin{array}{l}14 \\
5 \\
3 \\
3 \\
8\end{array}$ & $\begin{array}{l}42 \% \\
15 \% \\
9 \% \\
9 \% \\
24 \%\end{array}$ \\
\hline $\begin{array}{l}\text { Relaxing } \\
(n=31)\end{array}$ & $\begin{array}{l}\text { Toothache/ } \\
\text { sensitive tooth } \\
\text { Broken tooth } \\
\text { Other }\end{array}$ & $\begin{array}{l}24 \\
3 \\
4\end{array}$ & $\begin{array}{l}77 \% \\
10 \% \\
13 \%\end{array}$ & $\begin{array}{l}\text { Contact of } \\
\text { other people } \\
(n=21)\end{array}$ & $\begin{array}{l}\text { Missing tooth } \\
\text { Toothache/ } \\
\text { sensitive tooth } \\
\text { Bad position } \\
\text { Colour } \\
\text { Other }\end{array}$ & $\begin{array}{l}5 \\
3 \\
3 \\
3 \\
7 \\
7\end{array}$ & $\begin{array}{l}24 \% \\
14 \% \\
14 \% \\
14 \% \\
33 \%\end{array}$ \\
\hline
\end{tabular}

Half of them reported having used drugs. Cannabis, amphetamines and heroin were the three most popular drugs. Prisoners were also asked to report how often they consumed sweet items (cakes, sweets) and drank fizzy drinks on a weekly basis. Overall, 66\% of the participants had a high sugar intake, that is, consumed a serving of cakes or sweets or fizzy drinks at least six or more times a week.

Oral impacts were over two times more prevalent among women prisoners than in the ADHS (73\% and 34\% respectively reported at least one daily performance affected by oral conditions). The most commonly affected performances were eating (55\%), smiling (37\%), emotional stability (32\%) and relaxing (30\%) (Table 4). Toothache/sensitive tooth was the most prevalent perceived 'cause' of oral impacts in relation to eating, relaxing, carrying out usual role and emotional stability, while oral impacts on speaking, smiling, and enjoying contact with other people were primarily attributed to missing teeth by participants. Loose tooth/bleeding gums was the most commonly reported 'cause' of oral impacts on cleaning teeth/ dentures (Table 5).

In relation to the prison dental service over 90\% of these respondents reported that the prison dentist was not present enough and a similar proportion reported difficulty in getting a dental appointment. Almost all the respondents (97\%) reported that the waiting list to see a prison dentist was too long. Over 56\% of the sample interviewed were on the HMP Holloway dental waiting list at the time of the survey. Nearly half (48\%) had been on the waiting list between one to three months and almost a quarter (24\%) for more than three months. The sample was also asked their views on the overall quality of prison 


\section{Table 6 Oral health promotion actions in prisons}

Policy agenda to create oral health promoting prison environment

Food policy - improve quality and choice of healthy foods/drinks. Ensure healthier choices cheaper and appealing

Hygiene and snack provision - options available to prisoners are very limited and mostly unhealthy. Need to ensure appealing and affordable choices - for example, high concentration fluoride toothpaste, good quality toothbrushes, sugar free snacks and drinks

Ensure appropriate access to hygiene facilities - enable twice daily toothbrushing

Ensure access to health promotion services - for example, smoking cessation, drug rehabilitation

Ensure safety of leisure facilities - to reduce dental trauma and injury. Also appropriate supervision of prisoners to reduce violence and bullying

Medication - ensure sugar free choices available for all medications - for example, methadone

Staff training - integrate oral health into health promotion training

Ensure clinical dental service implementing evidence based preventive guidelines in line with Delivering better oral health ${ }^{14}$ - for example, application of fluoride varnishes

Ensure dental services using an appropriate team approach - skill mix with use of dental care professionals to deliver preventive care and support for behaviour change

Actions to promote self-care practices

Ensure adequate and up to date oral health information is available to prisoners to facilitate self-care practices for example, display of posters and leaflets

Incorporate oral health messages into other health promotion programmes implemented in prison for example, healthy eating initiatives

Establish health forums and other approaches to encourage prisoners to be more actively involved in maintaining their health and oral health - encourage prisoners to collectively voice their views on action needed to improve conditions in prison for health for example, snack options

dental services. The majority (93\%) complained about the long waiting times for routine dental treatment and many (82\%) were also unhappy with the waiting times for urgent dental treatment while in prison.

\section{DISCUSSION}

The results of this study confirmed the very poor state of the oral health among UK prisoners. In line with the findings from a systematic review ${ }^{2}$ and studies in Scotland ${ }^{4}$ and London ${ }^{12}$ this study has shown that female prisoners in HMP Holloway have poorer oral health status than the general female population. In addition, this study demonstrated that prisoners are more likely to engage in damaging oral health behaviours and that their oral health status has a significant impact on their daily life.

The prevalence of dental disease among the prison population studied was high. Individual components of the DMFT score were considered along with the total score. Missing teeth were the principal component of the prisoners' DMFT. However, we need to be cautious in the interpretation of the missing component, as it is a composite measure that may result from different oral conditions, including caries, periodontal diseases, impaction, trauma or orthodontic treatment. Although the DMFT of the prison population was similar to the DMFT of the female sample in the 2009
ADHS, the HMP Holloway population had fewer filled teeth and twice the number of decayed and unsound teeth. However, when compared with other surveys in Scottish's prisons ${ }^{4}$ and HMP Brixton, London, ${ }^{12}$ the results of this study are better. For instance, the number of decayed teeth $(2.5 \pm 2.5)$ was lower than in both Scottish and Brixton prisons (3.8 and $3.5 \pm 2.7$ respectively). Nevertheless, the results should be interpreted with caution, as the sampling method was different for each study.

Poor oral health has been related to dental attendance patterns and attitudes to treatment. ${ }^{13}$ Forty-one percent of the female prisoners reported visiting the dentist only when in trouble. In the ADHS, only $22 \%$ of the females attended the dentist when in trouble.

The oral health behaviours of the Holloway prisoners were a major cause for concern. Smoking, drug use and unhealthy diets are some of the factors involved in the aetiology of dental diseases. ${ }^{14}$ While HMP Holloway advocates and promotes healthy food options at mealtimes, the majority of participants reported that they had high sugar intakes between meals.

Conducting research in a prison environment is challenging in many ways. However, this study had a robust and carefully planned methodology. The clinical and questionnaire data collection used the same validated measures that were used in the ADHS, thereby enabling valid comparisons with the ADHS findings. ${ }^{11}$ The clinical examiner was trained and calibrated in line with the ADHS criteria. Lastly, the questionnaire was pilot tested before its use to ensure its acceptability and feasibility. In contrast, we also recognise the limitations of this study. The study sample was selected from one female prison (HMP Holloway), so caution needs to be taken in terms of the generalisability of the study findings. However, when comparing the total DMFT to other previous studies in prisons elsewhere in the $\mathrm{UK}^{3,12}$ our results are very similar and highlight the poor conditions of the oral health of prisoners. This would indicate that our findings are an accurate account of the oral health status of female prisoners. For ethical reasons our sampling method did not include the prison mother and baby unit. This is a particularly important and potentially very vulnerable segment of the prison population.

\section{IMPLICATIONS FOR ORAL HEALTH PROMOTION}

Public health evidence has shown that to address health inequalities, a multifaceted health improvement strategy is needed. ${ }^{15}$ Public health guidelines recommend holistic and strategic action to promote health and well-being in prisons. ${ }^{16-18}$ Unfortunately oral health is often a neglected component of general health promotion strategies. Oral health promotion activities therefore need to be integrated seamlessly with general public health action as they share common risks and determinants. ${ }^{19}$ A major challenge in how best to promote oral health in a prison environment is the reorientation to a preventive approach. Many reviews of the oral health literature have established the limitations of only providing clinical and health education support in reducing oral health inequalities. ${ }^{20-22}$ These reviews have focused on evidence from the general population but their findings equally apply to marginalised populations such as prisoners. In essence, strategies to promote better oral health in prisons need to adopt a dual approach: firstly, action to improve the prison environment to make it more of an oral health promoting setting, and 
secondly, action to develop and empower prisoners to maintain their oral health through enhanced self-care practices. Table 6 presents a summary of the actions that could be implemented to improve oral health in prisons.

The success of oral health promotion interventions in prisons is largely dependent upon effective team working across the various agencies working in prisons. It is essential that commissioners recognise the need for fully resourced oral health promotion activities in prisons as without adequate funding little can be achieved. Appropriate monitoring and evaluation systems need to be used to assess progress and develop models of good practice.

\section{CONCLUSIONS}

The results of this study have demonstrated the very poor state of the oral health of female prisoners in HMP Holloway. Urgent action is needed to improve this situation through a comprehensive oral health improvement strategy tailored for prisons. The health of prisoners is often considered as an indicator of the moral and ethical state of a country. ${ }^{23}$ Failure to address this major problem would be a very sad reflection on contemporary British life.

The prison survey was funded by the NHS Islington. The authors would like to thank $\mathrm{Mr}$ Richard Comerford, Interin Head of Healthcare and Drug Strategy at HMP Holloway, and Ms Stella Simpson, Deputy Head of Healhcare at HMP Holloway, for their logistic assistance and important support throughout the survey. We would like to extend our thanks to Laurence Wills and Sarabjit (Sonia) Labana for assisting with the field work.
We also would like to thank the women prisoners who agreed to participate and to other prison staff for their assistance in escorting the participants.

1. Watt $R$, Sheiham A. Inequalities in oral health: a review of the evidence and recommendations for action. Br Dent J 1999: 187: 6-12.

2. Walsh T, Tickle M, Milsom K, Buchanan K, Zoitopoulos L. An investigation of the nature of research into dental health in prisons: a systematic review. Br Dent J 2008; 204: 683-689.

3. Jones C M, Woods K, Neville J, Whittle J G. Denta health of prisoners in the north west of England in 2000: literature review and dental health survey results. Community Dent Health 2005; 22: 113-117.

4. Jones C M, McCann M, Nuggent Z. Scottish Prisons' Dental Health Survey 2002. Edinburgh: Scottish Executive, 2004

5. Department of Health, HM prison service. Strategy for modernising dental services for prisoners in England. London, DH, 2003. Online article available at http://webarchive.nationalarchives gov.uk/20130107105354/http://www.dh.gov. uk/en/Publicationsandstatistics/Publications/ PublicationsPolicyAndGuidance/DH_4005989 (accessed May 2013).

6. Department of Health. Choosing better oral health an oral health plan for England. London, Department of Health, 2005. Online article available at http:// webarchive.nationalarchives.gov.uk/20130107105354/ http://www.dh.gov.uk/prod_consum_dh/groups/ dh_digitalassets/@dh/@en/documents/digitalasset/ dh_4123253.pdf (accessed May 2013).

7. Ministry of Justice. Population in custody, monthly tables. June 2010 England and Wales. London: Ministry of Justice, 2010. Online information available at https://www.gov.uk/government/uploads/ system/uploads/attachment_data/file/163123/popcustody-june-10.pdf.pdf (accessed May 2013).

8. Adulyanon S, Vourapukjaru J, Sheiham A Ora impacts affecting daily performance in a low dental disease Thai population. Community Dent Oral Epidemiol 1996; 23: 385-389.

9. Office for National Statistics. Protocol for the 2009 Adult Dental Health Survey. London: ONS, 2009.

10. Monse $B$, Heinrich-Weltzien $R$, Benzian $H$, Holmgren $C$, van Palenstein Helderman W. PUFA - an index of clinical consequences of untreated dental caries. Community Dent Oral Epidemiol 2010; 38: 77-82.

11. Office for National Statistics, Social Survey Division and Information Centre for Health and Social Care, Adult Dental Health Survey, 2009 [computer file]. 2nd edn. Colchester, Essex: UK Data Archive, 2012.

12. Heidari $E$, Dickinson $C$, Wilson R, Fiske J. Oral health of remand prisoners in HMP Brixton, London.
Br Dent J 2007; 202: 1-6.

13. Sheridan J, Aggleton M, Carson T. Dental health and access to dental treatment: a comparison of drug users and non-drug users attending community pharmacies. Br Dent J 2001; 191: 453-457.

14. Department of Health, British Association for the Study of Community Dentistry. Delivering better oral health: an evidence-based toolkit for prevention. 2nd ed. London: DH, 2009. Online article available at http://webarchive.nationalarchives.gov. uk/20130107105354/http://www.dh.gov.uk/prod_ consum_dh/groups/dh_digitalassets/documents/ digitalasset/dh 102982.pdf (accessed May 2013).

15. World Health Organisation, Commission on Social Determinants of Health. Closing the gap in a generation: health equity through action on the social determinants of health. Final report. Geneva: WHO 2008. . Online report available at http://www.who. int/social_determinants/thecommission/finalreport/ en/index.html (accessed May 2013)

16. Department of Health. Health promoting prisons: a shared approach. London: DH, 2002. Online article available at http://webarchive.nationalarchives. gov.uk/20130107105354/http://www.dh.gov. uk/en/Publicationsandstatistics/Publications/ PublicationsPolicyAndGuidance/DH_4006230 (accessed May 2013).

17. Department of Health, HM prison service. Strategy for modernising dental services for prisoners in England. London: DH, 2003. Online article at http://webarchive.nationalarchives. gov.uk/20130107105354/http://www.dh.gov. uk/en/Publicationsandstatistics/Publications/ PublicationsPolicyAndGuidance/DH_4005989 (accessed May 2013).

18. Harvey $S$, Anderson B, Cantore S, King E, Malik F. Reforming prison dental services in England - a guide to good practice. London: PM, 2005. Online article available at http://www.ohrn.nhs.uk/conferences/past/D160905PCW.pdf (Accessed May 2013).

19. Watt R G, Sheiham A. Integrating the common risk factor approach into a social determinants framework. Community Dent Oral Epidemiol 2012; 40: 289-296.

20. Sprod A, Anderson R, Treasure E. Effective oral health promotion. Literature review. Cardiff: Health Promotion Wales, 1996.

21. Kay E, Locker D. A systematic review of the effectiveness of health promotion aimed at improving oral health. Community Dent Health 1998; 15: 132-144.

22. Watt R G, Marinho V. Does oral health promotion improve oral hygiene and gingival health? Periodontal 2000 2005; 37: 35-47.

23. Mendela N. Long walk to freedom. London: Abacus, 1995. 